\title{
An Economic Analysis of Coastal Beach Safety Information-Seeking Behavior
}

\author{
Abigail Kaminski, Kathleen P. Bell, Caroline L. Noblet, and \\ Keith S. Evans
}

We estimate a bivariate probit model using data from a survey of Maine and New Hampshire beachgoers to (i) assess the impact of exposure to and contact with beach waters on safety information-seeking behaviors, and (ii) compare information-seeking behaviors for surf conditions and water quality information. We find that individuals who engage in certain high-contact recreation activities (i.e., swimming, fishing, surfing) are more likely to seek out safety information and that some potential drivers of this behavior affect searches differently for surf conditions versus water quality information.

Key Words: cost-effective risk communication, information-seeking behavior, risk, water quality

Beaches are important economic, social, and cultural assets. Coastal beaches host a range of recreation activities, from wading in calm shallows to surfing in rough waters. These areas attract large numbers of visitors nationally: an estimated 43 percent of the U.S. population visited a beach between 2005 and 2009 (Cordell 2012). Those who recreate on beaches often travel great distances to visit, suggesting that they place a high economic value on these resources. Many studies estimate the value of a recreational day on beaches in diverse coastal systems across the nation. These estimates vary by region and study methods, and per-person-per-day values ${ }^{1}$ range from $\$ 24.22$ for beachgoers in San Diego County (Lew and Larson 2008), to $\$ 77.56$ for

\footnotetext{
Abigail Kaminski is a research associate at George Perkins Marsh Institute, Clark University. Kathleen P. Bell is a professor at the School of Economics, University of Maine. Caroline L. Noblet is an assistant professor at the School of Economics, University of Maine. Keith S. Evans is an assistant professor at the School of Economics, School of Marine Sciences, University of Maine. Correspondence: Abigail Kaminski " George Perkins Marsh Institute, Clark University - 950 Main Street, Worcester MA, 01610 - Phone: 508.751 .4639 - Email: akaminski@clarku.edu

This work originated from master's thesis research conducted through the School of Economics at the University of Maine. We are grateful to the participants of the 2016 Northeastern Agricultural and Resource Economics Association Coastal Economies Workshop, and to two anonymous reviewers for their insightful feedback. We acknowledge support from NSF (Award 11A1330691) and USDA National Institute of Food and Agriculture (Projects ME021518, ME021510 and ME021704).
}

The views expressed are the authors' and do not necessarily represent the policies or views of any sponsoring agencies.

All values adjusted to 2015 dollars

Agricultural and Resource Economics Review 46/2 (August 2017) 365-387

(C) The Author(s) 2017. This is an Open Access article, distributed under the terms of the Creative

Commons Attribution licence (http://creativecommons.org/licenses/by/4.0/), which permits unrestricted re-use, distribution, and reproduction in any medium, provided the original work is 
tourists on Florida beaches (Bell and Leeworthy 1990), to as much as $\$ 97.09$ for those on North Carolina beaches (Bin, Landry, Ellis, and Vogelsong 2005). When aggregated across the large population who visit coastal beaches, this value becomes substantial. Coastal tourism and recreation also support jobs and businesses in coastal communities and contribute significantly to national and state gross domestic products (National Oceanic and Atmospheric Administration (NOAA) 2015).

Environmental change affects coastal resources and the economic and cultural services they provide. A diverse and fluctuating set of problems related to human development and climate change affect water quality and surf conditions, which, in turn, affect the safety of coastal waters for recreation. Increasing levels of impervious surface, large-scale nutrient runoff, certain land-use changes, and failing or aging waste and transportation infrastructures can all have negative effects on coastal water quality (Mallin et al. 2000, Doney et al. 2012). Heavy precipitation events, which are forecasted to occur more frequently in the coming years, are linked to increases in risk of waterborne illness through recreational contact (Charron et al. 2004, Patz et al. 2008). Changes in nutrient loads in coastal waters and rising ocean temperatures are expected to cause increases in the duration, frequency, and severity of harmful algal blooms in fresh, estuarine, and marine waters ( $\mathrm{O}^{\prime} \mathrm{Neil}$ et al. 2012). Rising oceans are expected to lead to increases in riptide activity and dangerous sea life (Diaz 2006), and increases in ocean temperatures and changes in salinity are projected to expand the range of Vibrio $^{2}$ and other waterborne pathogens (Baker-Austin et al. 2013). As new environmental changes emerge, public health and safety risks on coastal beaches may increase in intensity and volume in response to human development near coastal regions and climate change; effective communication about safety issues on dynamic beach systems is increasingly both important and complex. Safety information about beach conditions can help users understand the inherent risks of recreating in coastal waters.

Risks on coastal beaches range in severity: riptides and high surf increase the likelihood of being injured or drowning while swimming (Leatherman and Leatherman 2011); exposure to pathogens in water can result in ailments ranging from skin rashes and gastrointestinal illness to - in very rare cases necrotizing fasciitis ${ }^{3}$ (Gomez et al. 2003, Wade et al. 2010). Risk of serious consequences from swimming in coastal waters is experienced differently across groups; immunocompromised individuals, children, and the elderly are

\footnotetext{
2 Vibrio is a group of bacteria found in coastal waters; it is most prevalent in the warmer months (May - October) and in areas with higher water temperatures. Vibrio infection can cause gastrointestinal distress or skin infections in humans who ingest or are exposed to the bacteria. <http://www.cdc.gov/vibrio/index.html>

3 Necrotizing fasciitis, often called 'flesh-eating bacteria,' is a skin infection that is very rare but can be life threatening. It can be contracted through contact with seawater that contains Vibrio vulnificus (Kuo, Shieh, Chiu, and Lee, 2007).
} 
typically at greatest risk of the more serious health and safety issues on the beach. Children are more likely to develop gastrointestinal illness after contact with contaminated beach water (Wade et al. 2008). Those who swim in the water and fully submerge are also at a higher risk for illness associated with the bacteria or pathogens in contaminated water than those who have lower levels of water contact (Collier et al. 2015). In addition, children and other weak or inexperienced swimmers are more likely to be injured or drown in riptides or rough surf (Gensini and Ashley 2010, Drozdzewski et al. 2015).

Beach safety information is communicated onsite through flags and signage, and off-site through forecasting and public health websites, beach condition hotlines, and local media sources such as newspaper or radio. Studies addressing water quality information-seeking behavior find many users are not aware of or do not seek out water quality information, and that many are misinformed about the quality of water at local beaches (Pendleton 2001, Pendleton, Martin, and Webster 2001, Pratap, Sarah, and Samuel 2013). Studies assessing the effectiveness of riptide and other dangerous surf communication report that, on average, less than half of users notice warning signs on the beach (Matthews, Andronaco, and Adams 2014, Brannstrom et al. 2015). While this limited information seeking may be efficient (i.e., consistent with small health risks), widespread gaps in understanding of visitor awareness, visitor health risks, beach and water conditions, and health outcomes all undermine assessment of current trends and raise questions about the design and performance of current programs.

Surprisingly, no published studies of which we are aware consider the decision to seek out water quality and surf conditions information together. Though the risks associated with surf conditions and water quality differ, both information types allow beachgoers to better understand and assess the safety of the same resource. Oftentimes this information is available in close proximity: water quality advisory signs and surf conditions flags are frequently co-located on lifeguard stands and can sometimes be found on the same website. By focusing studies on only one type of safety information, researchers forego interesting insights about those beachgoers who seek out different types of safety information and the ways that beachgoers value diverse types of beach safety information.

Responding to these broad and specific gaps in understanding, we employ economic methods to assess information-seeking behavior for water quality and surf conditions information. We explore the relationship between personal characteristics and information-seeking behaviors, focusing on: (i) how beachgoers' exposure to and contact with coastal beach waters relate to decisions to seek out safety information, and (ii) how the relationships between personal characteristics and information-seeking behaviors differ between water quality and surf conditions information. 


\section{Context}

Social science theory offers a valuable lens through which to view safety information-seeking behavior. Economic theory and research suggest that individuals seek out information when the costs of the information are outweighed by its expected benefits; information helps reduce the uncertainty associated with consumption decisions (Stigler 1961, Stiglitz 2000). Psychology and communications studies indicate that the costs associated with seeking out information can be complex. Individuals may actively choose to ignore or avoid information if they perceive that the information will cause them stress or anxiety (Case et al. 2005). Individual perceptions about the usefulness of information to decision-making can affect whether or not an individual actively seeks out information, and may be more influential than personal perceptions about a lack of knowledge about the issue at hand (Osimani 2012).

The value of safety information for an individual varies based on personal perceptions of risk as well as the factors that influence personal recreational risk (Alberini et al. 2009). Information and perceptions about site condition, safety, and environmental quality have an impact on the way recreators make visitation decisions (Freeman III, Herriges, and Kling 2014). Safety information may influence the way individuals perceive the environmental or physical quality of a recreation site. Using data collected to describe actual waterquality testing and advisories, research on beach recreation choices find that beachgoers are less likely to visit a beach with poor water quality history when making decisions between beaches (Murray, Sohngen, and Pendleton 2001, Yeh, Haab, and Sohngen 2006, Parsons et al. 2009, Song, Lupi, and Kaplowitz 2010). Although few studies include perceptions of quality in their models, there is some evidence that water quality perceptions are also negatively correlated with decisions to take day trips to a beach (Jeon et al. 2005). Some studies suggest that the relationship between safety and visitation decisions differs depending on recreational activity choice, family composition, and other visitation preferences (Jeon et al. 2005, Hilger and Hanemann 2006, Beharry-Borg and Scarpa 2010). Beachgoers generally prefer safe swimming conditions, in terms of both water quality and wave height (Penn et al. 2016), though, preference for calmer waters is not pronounced when considering smaller wave heights (Loomis and Santiago 2013).

Given the results of past studies that suggest many users are not aware of or do not seek out water quality and surf conditions information (Pendleton 2001, Pendleton, Martin, and Webster 2001, Pratap, Sarah, and Samuel 2013, Matthews, Andronaco, and Adams 2014, Brannstrom et al. 2015), there is much that can be learned from focused research on information-seeking behaviors, the implications of such behavior on recreation demand models of beach visitation and their characterization of welfare impacts from changes in environmental quality. Prior studies, which often assume full or homogenous uptake of advisory information, offer limited guidance. Jakus and Shaw 
(2003) and Leggett (2002) are notable exceptions, providing interesting guidance for subsequent research. We envision many ways in which the search for safety information could change recreation demand models (e.g., new trip costs, additional choice variable(s), quality, heterogeneity, uncertainty). Nonetheless, a full recreation demand model is beyond the scope of this study. Instead, we focus explicitly on modeling decisions to seek out beach safety information. By doing so, we contribute to the broader recreation demand literature and draw attention to the incomplete understanding of what drives beachgoers to seek out beach safety information. The theoretical basis of our empirical analyses emerges from economic theory, noting that people seek out information when the expected benefits of the information outweigh the expected costs (Stigler 1961, Stiglitz 2000). Using unique data that document whether or not beachgoers seek different types of beach safety information, we consider the influences of socioeconomic characteristics, including income, and individual variation in exposure to beach resources on expected benefits and costs and, ultimately, the net expected returns from information search.

\section{Methods}

We use survey data to explore the potential importance of contact with and exposure to beach resources on decisions to seek out safety information and to examine any differences in factors that influence information-seeking behaviors across two types of beach safety information (surf conditions and water quality). A bivariate probit model provides the statistical foundation for our analysis, capturing the potentially joint, discrete decisions to seek out different types of beach safety information.

\section{Survey Design, Administration, and Sample}

Our analysis draws from a 2014 web survey designed to collect beach visitation information from Maine and New Hampshire beachgoers, to fill in key information gaps identified by regional stakeholders and to support research addressing a range of human behavior and attitudes relating to beach use and beach safety. We developed the questionnaire following tailored scientific design principles (Dillman, Smyth, and Christian 2014) and refined the content iteratively with input from stakeholders and colleagues across disciplines and institutions. The web survey gathered information from beachgoers who participated in a short intercept survey conducted in the summer of 2014 on three beach systems in southern Maine and coastal New Hampshire and agreed to participate in a follow-up survey. We contacted 1,259 potential respondents through email and asked them to complete a web-based survey. We collected responses from 435 beachgoers, 336 of whom answered the survey in full (a completed response rate of 29 percent). Because respondents were not required to answer all questions throughout 
the survey, some of these respondents were dropped, and our final sample for this analysis consists of 299 beachgoers.

Our sample of beachgoers represents those who participated in the intercept survey, provided their email address for further contact, and completed the follow-up survey in full; as such they can be considered a motivated and engaged beachgoer group and do not necessarily represent the coastal beachgoer population in Southern Maine and New Hampshire. Our sample demographics closely match those of the intercept sample. The sample consists of beachgoers primarily from northeast United States and southeast Canada.

\section{Dependent Variable(s)}

The two binary dependent variables of our bivariate probit model describe whether or not beachgoers broadly seek water quality and surf conditions safety information (Table 1). To collect data on beachgoers' informationseeking behavior, we asked respondents whether or not they seek out beach safety information and asked which type of information. Specifically, we model responses to the question: 'Do you seek out beach safety information, and which type of information do you seek out?' Respondents could either seek out: (i) water quality information only, (ii) surf conditions information only, (iii) both water quality and surf conditions information, or (iv) no safety information at all. Using responses to these four options, we create two binary dependent variables indicating whether respondents do or do not seek water quality and surf conditions information. We adopt the bivariate probit modeling specification to allow for distinct, though correlated, individual search behaviors for these two types of safety information.

\section{Explanatory variables}

We break the factors that could impact information-seeking behavior into two categories: (i) socioeconomic and personal characteristics, and (ii) exposure or contact proxy variables (Table 1). Socioeconomic factors affect the costs of searching for and processing information and the anticipated benefits of knowing that information. Exposure and contact with coastal water affects an individual's health and safety risks and the potential value of information to the individual.

As specified, INCOME and EDUCATION will affect the time costs of seeking out information. A higher income implies higher time costs of searching for information. These time costs may be proportionally less important than the time costs for those with lower income levels, as those with lower incomes may have greater constraints on the time that they have available to perform information searches. We hypothesize that education will reduce the costs of safety information. Those with higher education levels may be better prepared to search for and process information. 
Table 1. Beach Safety Information Search: Variable Descriptions and Dataset Values

\begin{tabular}{lcc}
\hline $\begin{array}{l}\text { Variable } \\
\text { name }\end{array}$ & $\begin{array}{c}\text { Mean dataset } \\
\text { value }\end{array}$ & \multicolumn{1}{c}{ Variable description } \\
\hline Information search & \\
\hline SURF INFO & $50 \%$ & $\begin{array}{l}1 \text { if respondent seeks out surf conditions information; } \\
0 \text { otherwise } \\
1 \text { if respondent seeks out water quality information; } \\
\text { 0 otherwise }\end{array}$ \\
WQ INFO & $26 \%$ &
\end{tabular}

Socioeconomic characteristics

\begin{tabular}{|c|c|c|}
\hline INCOME & 119.5 & $\begin{array}{l}\text { Annual income in the thousands, calculated as the } \\
\text { midpoint of } 10 \text { income brackets ranging from } \\
\$ 10,000 \text { to } \$ 200,000 \text {; lower bound of } \$ 10,000 \text { and an } \\
\text { upper bound of } \$ 250,000\end{array}$ \\
\hline AGE & 50.40 & Age of respondent \\
\hline EDUCATION & 16.29 & $\begin{array}{l}\text { Approximate years of education }(10=\text { less than high } \\
\text { school; } 12=\text { high school graduate; } 16=\text { bachelor's } \\
\text { degree; } 20=\text { graduate degree) }\end{array}$ \\
\hline FEMALE & $63 \%$ & 1 if female; 0 otherwise \\
\hline ENVORG & $16 \%$ & $\begin{array}{l}1 \text { if member of an environmental organization; } \\
0 \text { otherwise }\end{array}$ \\
\hline CANADIAN & $14 \%$ & $\begin{array}{l}1 \text { if respondent has a Canadian home address; } \\
0 \text { otherwise }\end{array}$ \\
\hline CHILD & $28 \%$ & $\begin{array}{l}1 \text { if household contains at least one child under } 13 \text {; } \\
0 \text { otherwise }\end{array}$ \\
\hline RISK INDEX & 10.55 & $\begin{array}{l}\text { Summed responses to a series of } 4 \text { questions assessing } \\
\text { respondents' risk behaviors (summed values ranged } \\
\text { from } 4 \text { to 28); higher values indicate tendency } \\
\text { toward more risky behavior }\end{array}$ \\
\hline
\end{tabular}

Exposure to beach water resources

$\begin{array}{lcl}\text { FULL DAY } & 41 \% & \begin{array}{l}1 \text { if respondent spends more than } 5 \text { hours on the beach } \\ \text { on an average beach trip; } 0 \text { otherwise }\end{array} \\ \text { SWIMMING } & 82 \% & \begin{array}{r}1 \text { if respondent engages in coastal swimming; } \\ \text { 0 otherwise }\end{array} \\ \text { FISHING } & 17 \% & \begin{array}{l}1 \text { if respondent engages in coastal fishing; } 0 \text { otherwise } \\ \text { SURFING }\end{array} 1 \text { if respondent surfs; } 0 \text { otherwise } \\ \text { FREQVIS } & 45 \% & \begin{array}{l}1 \text { if respondent visits an ocean beach more than once a } \\ \text { month; } 0 \text { otherwise } \\ \text { if respondent lives within } 20 \text { km of the coast; } \\ \text { 0 otherwise }\end{array} \\ \text { LIVES COAST } & 18 \% & \end{array}$

Note: Sample of Southern Maine and New Hampshire coastal beachgoers $(n=299)$ 
AGE could affect the decision to seek out information through differences in risk perceptions between cohorts and the connections that different age groups make between risky behavior and health effects. Younger populations tend to underestimate their risk of health effects when engaging in some risky behaviors (Viscusi 1991). The relationship between age, exposure to pollutants, and health is complex and can vary depending on the specific disease or safety issue; for example, belief that air pollution causes asthma decreases with age, while belief that air pollution causes bronchitis increases with age (Howel et al. 2003). Age decreased the likelihood of eating risky foods but had little effect on perceptions of risk, except in older cohorts, where risk perceptions were lower (Fein et al. 2011). We include AGE2 to allow for a nonlinear relationship between age and information-seeking behavior; we expect that as age increases, the probability that an individual will seek out safety information will increase but will do so at a decreasing rate and, at a certain point, we might see the effect reverse.

Many studies find that gender affects information-seeking behavior, and in the case of safety and environmental issues, this is often because risk attitudes or perceptions differ between men and women. We expect that women (FEMALE) will seek out beach safety information at a higher rate than men. Women are generally found to engage in fewer risky behaviors than men. especially in recreation and health domains (Byrnes, Miller, and Schafer 1999, Nicholson et al. 2005, Harris, Jenkins, and Glaser 2006). It follows that women will place a higher value on safety information and will be more likely to seek it out.

Belonging to an environmental organization (ENVIRON ORG) could indicate increased awareness of environmental issues, and there is some evidence of a positive correlation between environmental attitudes and environmental knowledge (Arcury 1990). We expect that environmental group membership will increase the likelihood of seeking out safety information, because users in these groups could be more concerned with and knowledgeable about environmental issues such as coastal water quality impairment.

Those who are CANADIAN could seek out information differently from U.S. citizens because of cultural differences. Canadians are generally more rule abiding and risk averse than American citizens (Lipset 1991); we expect that this will be reflected in their information-seeking behavior, and that Canadians will be more likely to seek out safety information than Americans.

We expect that individuals with children (CHILD) will be more likely to seek out either (or both) types of safety information because children face a greater risk of injury from surf conditions (Gensini and Ashley 2010, Drozdzewski et al. 2015) and illness due to exposure to pathogens (Wade et al. 2008).

We also include a RISK INDEX variable that aims to provide an approximate measurement of an individual's risk behavior. Respondents were asked to indicate on a scale from $1-7$, where $1=$ never and $7=$ often, how often they engage in certain potentially risky behaviors, including not washing hands before eating, exposing themselves to the sun without sunscreen, eating raw 
foods, and eating expired foods. We sum the responses to this question to create a risk index. ${ }^{4}$ We expect that as the risk index increases, i.e., the more risky the behaviors the individual reports engaging in, the likelihood that the individual will seek out information of either type will decrease, as not seeking out safety information can be interpreted as a risky behavior in itself.

Exposure to or contact with beaches or beach water could have an effect on the risks that individuals face on beaches, in turn, affecting the benefits associated with safety information. However, the risk literature notes that those who participate in and regard recreational activities positively can underestimate the risks associated with those activities (Slovic et al. 2004, McComas 2006). Disconnects between actual risk levels and perceived levels of risk can emerge based on media coverage or personal recall of incidences, biasing beachgoers' risk perceptions, either causing them to underestimate or overestimate the probability that they will experience a given risky event (Fischhoff, Bostrom and Quadrel 1993, McComas 2006, Sunstein and Zeckhauser 2011). ${ }^{5}$ We include several proxies for exposure to beach resources, including both intensity of exposure (FULL DAY, FISHING, SWIMMING, SURFING), and frequency of exposure (FREQVIS). We also include a dummy variable to identify individuals who live near the coast (LIVES COAST), because we expect these users will also be indirectly exposed to ocean resources more often than those who live further away. We hypothesize that these exposure and contact variables will influence the perceived risk of illness or injury on beaches, in one of two ways. These users may understand that they are at a higher risk of becoming sick or injured from recreating in ocean waters, perhaps recalling past experiences where they have had safety issues during beach recreation. They may seek out safety information to help mitigate this risk. Alternatively, if beachgoers have positive associations with coastal recreation, they may assume that their risks are low and will choose not to seek out safety information. There may be differences between water quality and surf conditions information-seeking behaviors, as there are different risks associated with each, and there may be differences in past experiences linked with each.

\footnotetext{
4 We tested the variables we include in our risk index for reliability using Chronbach's alpha, which is used to test the strength of the relationship between multiple related variables. The Chronbach's alpha value for the four risk variables is 0.414 . Variables with a strong relationship typically have Chronbach's alpha values of 0.7 or above. With these test results in mind, we made the decision to sum the variables, rather than use the average value across the four variables. Summing the variables allows for us to better model ranges of responses, while averaging may smooth responses and eliminate interesting variation.

5 The most commonly referenced example relates to shark attacks. In 2001, there was an increase in media coverage of shark attacks and an associated fear of swimming in ocean waters by the general public. There was no statistical increased risk of shark attack in 2001 (and some statisticians note that there were actually fewer recorded shark attacks than in previous years).
} 


\section{Analysis}

We model beach safety information-seeking behavior using a bivariate probit model, where we assume that the net expected return from a particular information-seeking behavior ( $\mathrm{Y}^{*}{ }_{\text {iWATER }}$ and $\mathrm{Y}^{*}{ }_{\text {iSURF }}$ ) is a function of individual characteristics $\left(\mathrm{X}_{\mathrm{i}}\right)$, and unobservable factors $\left(\varepsilon_{\mathrm{ij}}\right)$. We represent individual characteristics $\left(\mathrm{X}_{\mathrm{i}}\right)$ using vectors of socioeconomic characteristics, including income and individual variation in exposure to water on the beach. Following Greene (2003), the specification for the bivariate probit model becomes:

$$
\begin{gathered}
Y_{\text {iWATER }}^{*}=\beta_{\text {WATER }}^{\prime} X_{i}+\varepsilon_{i W A T E R} ; Y_{\text {iWATER }}=1 \text { if } Y_{\text {iWATER }}^{*}>0,0 \text { otherwise; } \\
Y_{\text {iSURF }}^{*}=\beta_{\text {SURF }}^{\prime} X_{i}+\varepsilon_{i S U R F} ; Y_{i S U R F}=1 \text { if } Y_{\text {iSURF }}^{*}>0,0 \text { otherwise }
\end{gathered}
$$

where we assign the net return derived by individual $i$ from selecting a given information-seeking alternative $j$ (i.e., WATER or SURF) as $Y_{i j}^{*}$ and denote this as a linear, additive function of $\mathrm{X}_{\mathrm{i}}$, a vector of associated parameters to be estimated $\left(\beta_{\mathrm{j}}\right)$, and $\varepsilon_{\mathrm{ij}}$. We assume $\varepsilon_{\text {WATER }}$ and $\varepsilon_{\text {SURF }}$ are distributed bivariate normal, with expected value of $\varepsilon_{\mathrm{j}}$ equal to 0 and variance of $\varepsilon_{\mathrm{j}}$ equal to 1 . We specify the covariance between $\varepsilon_{\text {WATER }}$ and $\varepsilon_{\text {SURF }}$ to be a parameter to be estimated $\rho$. This specification allows for the disturbances to be correlated across the two equations.

We estimate the bivariate probit model and parameters using maximum likelihood estimation. Prior to estimation, we generated descriptive statistics for the dependent and explanatory variables and test for multicollinearity among the explanatory variables (as a result, we decide to drop education from the final models because of its correlation with income). We conducted multiple forms of robustness checks. We estimate binary probit models (without correlated disturbances) for comparison and contrast; these estimates also informed formal statistical testing of $\rho$ as significantly different from zero. In addition to the binary probit models, we estimate a multinomial logit (MNL) model across the original four information-seeking response options. We ultimately decide that the MNL approach was inappropriate due to the MNL's independence of irrelevant alternatives (IIA) property, which stipulates that the relative probability of choosing one alternative over another is independent of any other alternative (Hausman and McFadden 1984, Train 2009). In our case, the similarity of three of the four choice categories raised concerns about the MNL model's treatment of substitution across these options. Instead, we opt to combine choice categories and focus on decisions to seek out water quality safety information and surf conditions information within the bivariate probit framework. To address our two focal research questions, we complete joint and individual statistical tests of the estimated parameters. 


\section{Results and Discussion}

The majority of our sample report that they seek out some type of beach safety information, with more seeking out surf conditions than water quality conditions; 34 percent seek out only surf conditions, 10 percent seek out only water quality conditions, and 16 percent seek out both types of information. The remainder our sample ( 40 percent) seek out neither type of beach safety information. The results of the bivariate probit model reveal interesting patterns in the factors that affect decisions to seek out safety information (see Table 2 for full binary and bivariate probit results, and Table 3 for key bivariate probit results). Global significance tests reveal that the model outperforms the intercept-only model (Wald test statistic $=88.46$; $\mathrm{p}$-value $=<0.001$ ). Further, likelihood ratio testing rejects the hypothesis that $\rho$ equals 0 (likelihood ratio test $=8.55$; $p$-value $=0.004$ ), favoring the bivariate probit specification over the distinct binary probit models (shown in Table 2). Our results were consistent across the binary probit and MNL specifications of the model (full results are available upon request).

We discuss statistically significant results in greater detail below (coefficients with p-values of 10 percent or less); some results are not discussed at length because of statistical insignificance. We include AGE and AGE2 in our models to allow for varying effects of age on decisions to seek out information (i.e., we expect age to affect decision-making, but that this effect will lessen at higher ages). We jointly test the hypothesis that the parameters associated with AGE and AGE2 are statistically significantly different than zero, and fail to reject the null hypothesis at the 5 percent level; although the parameter associated with AGE2 is significant in some of our results, we do not discuss the effect of age on information-seeking, because the joint results are insignificant.

To address our first research question, 'How do beachgoers' exposure to and contact with beach resources relate to decisions to seek out beach safety information?' we test the joint hypothesis that the coefficients for the exposure and contact proxy variables are all equal to zero and scrutinize individual coefficient estimates as well. Joint tests of significance by equation reject the hypothesis that exposure and contact coefficients are equal to zero (WATER Wald test statistic $=24.11$, p-value $<0.001$; SURF Wald test statistic $=42.50$, p-value $<0.001$ ). Further, consistent with our expectations, our model reveals many statistically significant associations between information search and our high-contact recreation variables (swimming, fishing and surfing). Those who have high contact with water resources are also at a greater risk of illness or injury from hazardous water quality conditions, and safety information could be more valuable to their decisions to engage in these activities on a given day. Those who swim in coastal waters are more likely to seek out all types of safety information; swimmers are more likely to be exposed to pathogens in water or be affected by high surf conditions than those beachgoers who do not swim. Those who fish in 
Table 2. Beach Safety Information-Seeking Behavior Model Results

\begin{tabular}{|c|c|c|c|c|}
\hline \multirow[b]{2}{*}{ Variable } & \multicolumn{2}{|c|}{ Binary Probit } & \multicolumn{2}{|c|}{ Bivariate Probit } \\
\hline & WATER & SURF & WATER & SURF \\
\hline \multirow[t]{2}{*}{ AGE } & -0.063 & -0.060 & -0.061 & -0.060 \\
\hline & $(0.043)$ & $(0.044)$ & $(0.428)$ & $(0.044)$ \\
\hline \multirow[t]{2}{*}{ AGE2 } & 0.001 & 0.001* & 0.001 & 0.001* \\
\hline & $(<0.001)$ & $(<0.001)$ & $(<0.001)$ & $(<0.001)$ \\
\hline \multirow[t]{2}{*}{ FEMALE } & -0.214 & $0.463^{* * *}$ & -0.218 & $0.491^{* * *}$ \\
\hline & $(0.181)$ & $(0.178)$ & $(0.181)$ & $(0.179)$ \\
\hline \multirow[t]{2}{*}{ INCOME } & $0.002^{*}$ & -0.001 & 0.002 & -0.001 \\
\hline & $(0.001)$ & $(0.001)$ & $(0.001)$ & $(0.001)$ \\
\hline \multirow[t]{2}{*}{ ENVORG } & 0.151 & $0.460 * *$ & 0.152 & $0.471^{* *}$ \\
\hline & $(0.227)$ & $(0.222)$ & $(0.226)$ & $(0.221)$ \\
\hline \multirow[t]{2}{*}{ CANADIAN } & $0.603^{* *}$ & -0.361 & $0.634^{* *}$ & -0.375 \\
\hline & $(0.262)$ & $(0.272)$ & $(0.263)$ & $(0.272)$ \\
\hline \multirow[t]{2}{*}{ CHILD } & -0.138 & -0.074 & -0.112 & -0.113 \\
\hline & $(0.260)$ & $(0.241)$ & $(0.208)$ & $(0.199)$ \\
\hline \multirow[t]{2}{*}{ RISK INDEX } & -0.011 & $-0.045^{* *}$ & -0.010 & $-0.043^{* *}$ \\
\hline & $(0.222)$ & $(0.021)$ & $(0.022)$ & $(0.021)$ \\
\hline \multirow[t]{2}{*}{ FULL DAY } & -0.063 & $0.331^{* *}$ & -0.081 & $0.328 * *$ \\
\hline & $(0.175)$ & $(0.167)$ & $(0.176)$ & $(0.167)$ \\
\hline \multirow[t]{2}{*}{ SWIMMING } & $0.642^{* *}$ & $0.598^{* * *}$ & $0.684^{* * *}$ & $0.636^{* * *}$ \\
\hline & $(0.253)$ & $(0.229)$ & $(0.256)$ & $(0.230)$ \\
\hline \multirow[t]{2}{*}{ FISHING } & $0.550^{* * *}$ & 0.380* & $0.557^{* *}$ & 0.401* \\
\hline & $(0.213)$ & $(0.221)$ & $(0.216)$ & $(0.224)$ \\
\hline \multirow[t]{2}{*}{ SURFING } & $-0.763^{* * *}$ & $0.601^{* * *}$ & $-0.748 * * *$ & $0.621^{* * *}$ \\
\hline & $(0.267)$ & $(0.231)$ & $(0.265)$ & $(0.232)$ \\
\hline \multirow[t]{2}{*}{ FREQVIS } & 0.297 & $0.344^{* *}$ & $0.315^{*}$ & $0.332 *$ \\
\hline & $(0.187)$ & $(0.172)$ & $(0.188)$ & $(0.173)$ \\
\hline \multirow[t]{2}{*}{ LIVES COAST } & -0.070 & $-0.755^{* * *}$ & -0.078 & $-0.747 * * *$ \\
\hline & $(0.224)$ & $(0.225)$ & $(0.222)$ & $(0.224)$ \\
\hline$\rho$ & - & - & \multicolumn{2}{|c|}{$0.324^{* * *}$} \\
\hline AIC & 336.635 & 373.437 & \multicolumn{2}{|c|}{703.335} \\
\hline Log likelihood & -153.318 & -171.718 & \multicolumn{2}{|c|}{-320.629} \\
\hline Global Wald Test & $30.230 * * *$ & $56.550 * * *$ & $30.550 * * *$ & $57.470 * * *$ \\
\hline
\end{tabular}

Notes: Single asterisks, double asterisks, and triple asterisks indicate statistical significance at the 10percent, 5-percent and 1-percent level, respectively. Significant results are also bolded in the table. The numbers in parentheses beneath the parameter estimates are standard errors. For the bivariate probit model, rho $(\rho)$ is the correlation of the errors between the two model specifications. 
coastal waters are also more likely to seek out both surf conditions and water quality conditions; the quality of a day for fishing may be affected by surf conditions, and it is logical that those who fish would want to ensure that their catch was coming from reliably healthy waters.

Those who surf in coastal waters are more likely to seek out surf conditions information; surf conditions information influences decisions to surf, though it may be that these users are not seeking out this information to avoid risk, and high surf positively influences their decision to make a trip to the beach. Surprisingly, we observe a negative relationship between surfing and seeking out water quality information. This is counter to what we might expect from the risk profiles of recreation activities: surfing presents greater risks of illness from exposure to polluted waters than other beach recreation activities, as surfers are more likely to involuntarily ingest water or unexpectedly submerge than typical recreational swimmers (Turbow, Kent, and Jiang 2008, Tseng and Jiang 2012, Harding et al. 2015). In fact, high surf frequently occurs after or during a storm event when water quality is often compromised (Tseng and Jiang 2012). However, it is likely that surfers are less risk averse than the general population when it comes to beach recreation; they seek out information not to mitigate their risk but to find whether the conditions are favorable for surfing, and water quality information might not serve a purpose to surfers in this context. We find some evidence of this in our sample: the 'risk index' of surfers is slightly higher than that of nonsurfers; we expect that actual beach risk perceptions differ more dramatically between surfers and nonsurfers, as our risk index does not include recreation-based risk-taking behaviors. Surfers as a group can be considered sensation seekers and risk takers (Stranger 1999), and many surfers consider surfing to be a risky sport (Scott 2016, Scott and Rogers 2016b). Some evidence suggests that surfers have knowingly chosen to surf during a water quality advisory (29 percent to 37 percent, depending on the study and region) or when they otherwise suspected that the water quality was impaired (Harding et al. 2015, Scott 2016, Scott and Rogers 2016a). Additionally, surfing is popular in the off season, when beach water quality conditions are not regularly monitored or communicated to the public.

Indirect exposure to beaches also affects information-seeking behaviors. Those who visit beaches at least once per month are more likely to seek out surf conditions information, while those who live within $20 \mathrm{~km}$ of the coast are less likely to seek out surf conditions information. This result is interesting - it may be that those who live by the beach rely on experiential knowledge or their familiarity with beaches to make decisions about visiting a beach (Park and Lessig 1981, Samuelson and Zeckhauser 1988, Haab and Hicks 1999, Hicks and Strand 2000, Parsons, Massey and Tomasi 2000). It could also be that these beachgoers have a beach that they consistently visit, and they may use their past experiences at this beach or other beaches to inform their decisions about safety, rather than formal information (Fischhoff, Bostrom and Quadrel 1993, McComas 2006, Sunstein and Zeckhauser 2011). 
Table 3. Statistically Significant Factors Affecting Surf Conditions and Water Quality Information-Seeking Behavior, Bivariate Probit Model

\begin{tabular}{|c|c|c|c|}
\hline & Variable & SURF CONDITIONS & WATER QUALITY \\
\hline \multirow[t]{4}{*}{ Impact BOTH surf conditions and water quality information-seeking behavior } & SWIMMING & + & + \\
\hline & FISHING & + & + \\
\hline & SURFING & + & - \\
\hline & FREQVIS & + & + \\
\hline \multirow[t]{5}{*}{ Impact ONLY surf conditions information-seeking behavior } & ENVORG & + & \\
\hline & FULL DAY & + & \\
\hline & FEMALE & + & \\
\hline & LIVES COAST & - & \\
\hline & RISK INDEX & - & \\
\hline Impacts ONLY water quality information-seeking behavior & CANADIAN & & + \\
\hline
\end{tabular}

Notes: A ( + ) indicates that the variable is positive, and statistically significant at the 10 -percent level, a (-) indicates the variable is negative, and statistically significant at the 10-percent level, and a blank result indicates that the variable is not statistically significant at the 10-percent level. 
To address our second research question, 'How do the relationships between personal characteristics and decisions to seek out safety information differ between water quality information and surf conditions information?' we also use tests of joint parameter significance and scrutinize individual parameter estimates (Table 4). We test the null hypotheses that the coefficients for each variable are equal across the two different models (i.e., types of safety information). Specifically, we test for differences between surf conditions and water quality information coefficient values. We conclude that there are some differences in the factors that influence decisions to seek out different types of safety information.

Of the socioeconomic variables, FEMALE, INCOME, and CANADIAN coefficients are significantly different between water quality and surf conditions. Females are more likely to seek out surf conditions information; this generally aligns with our expectations, as females are typically more risk averse and will seek out safety information in accordance with their risk profiles (Halek, Martin, and Eisenhauer 2001, Eckel and Grossman 2008). However, we expect this relationship to hold between females and water quality information as well, and our results indicate a negative, though insignificant, relationship between females and water quality information. We find that Canadians are more likely to seek out water quality information. In addition to sociocultural differences between Canadians and Americans (Lipset 1990), these results may reflect differences in the way water quality information is displayed on Canadian beaches. Twenty-six beaches in Canada are certified 'Blue Flag' beaches, though most of these are Great Lakes beaches; Blue Flag beaches meet a set of criteria that includes environmental education outreach and compliance with rigorous water quality monitoring and communication standards. Currently, no U.S. beaches participate in the Blue Flag program, and this may help to explain the difference in water quality information-seeking behaviors between Canadians and U.S. citizens.

There are also some significant differences in the effect of exposure and contact proxy variables across the water quality and surf models. The SURFING coefficients are statistically significantly different, aligning with our prior findings on contact and exposure and other studies of surfers (Stranger 1999, Harding et al. 2015, Scott 2016). Notably, those who surf at coastal beaches are more likely to seek out surf conditions information and less likely to seek out water quality information. We also find a statistically significant difference between the coefficients on LIVES COAST in the two equations. Though the coefficient on this variable is negative in water quality and surf conditions models, the LIVES COAST coefficient is only statistically significant and negative in the surf conditions model.

In addition to reviewing our regression results in the context of our research questions, we acknowledge the surprising result, generally, of finding no association between having children in the household (CHILD) and information-seeking behavior. This goes against our initial expectations of parents to be more likely to seek out safety information. Alberini et al. 
Table 4. Assessing Differences in Factors Influencing Information-Seeking Behaviors

\begin{tabular}{|c|c|c|c|}
\hline \multirow[b]{2}{*}{ Variable } & \multicolumn{3}{|c|}{ Bivariate Probit Parameter Estimates } \\
\hline & WATER & SURF & Wald Test Statistic \\
\hline AGE & -0.061 & -0.060 & $<0.00$ \\
\hline AGE2 & 0.001 & 0.001* & \\
\hline FEMALE & -0.218 & $0.491 * * *$ & $9.34^{* * *}$ \\
\hline INCOME & 0.002 & -0.001 & $3.02 *$ \\
\hline ENVORG & 0.152 & $0.471^{* *}$ & 1.23 \\
\hline CANADIAN & $0.634^{* *}$ & -0.375 & $8.55^{* * *}$ \\
\hline CHILD & -0.112 & -0.113 & $<0.00$ \\
\hline RISK INDEX & -0.010 & $-0.043 * *$ & 1.44 \\
\hline FULL DAY & -0.081 & $0.328 * *$ & $3.40 *$ \\
\hline SWIMMING & $0.684 * * *$ & $0.636^{* * *}$ & 0.02 \\
\hline FISHING & $0.557 * *$ & $0.401^{*}$ & 0.31 \\
\hline SURFING & $-0.748 * * *$ & $0.621 * * *$ & $17.57^{* * *}$ \\
\hline FREQVIS & $0.315^{*}$ & $0.332^{*}$ & 0.01 \\
\hline LIVES COAST & -0.078 & $-0.747 * * *$ & $5.42^{* *}$ \\
\hline
\end{tabular}

Notes: The Wald test statistics displayed in this table are the result of a series of Wald tests where the null hypothesis is that the coefficient values are equal across water quality and surf models. Single asterisks, double asterisks and triple asterisks indicate statistical significance at the 10-percent, 5-percent, and 1-percent level, respectively. Significant Wald test results are also bolded in the table. 
(2009) find a negative relationship between the value of avalanche safety information and parents of children, and Hilger and Hannemann (2008) find that families with children have a lower willingness to pay for improvements in water quality on beaches. Given that children are at a higher risk for multiple health and safety hazards in recreation contexts, the relationship between information-seeking behaviors and the presence of children in the household merits future investigation.

\section{Conclusions}

A greater proportion of beachgoers seek out surf conditions information compared with water quality information, and this, in addition to our regression results, suggests that beachgoers regard the net returns from each type of safety information differently. Those who engage in certain highcontact recreation activities in the ocean (swimming, fishing), are more likely to seek out either type of safety information; these results are encouraging from a public health and safety perspective, as we expect these beachgoers to be at a higher risk on the beach than those who have less water contact. Our findings with respect to surfers (positive association with surfing conditions information-seeking; negative association with water quality informationseeking) provide additional support for prior research findings encouraging more risk communication with these recreators (Harding et al. 2015, Scott 2016, Scott and Rogers 2016b). Jointly communicating information about water quality with surf conditions information may allow this information to reach a broader audience. Given uncertainty about future coastal safety conditions, which can be impacted by environmental changes as well as changes in surrounding communities' development patterns, we cannot assume that beach recreation risks today will reflect those of tomorrow. Identifying vulnerable beachgoers who may not be actively seeking safety information (e.g., parents of young children) and developing communication plans to reach these beachgoers, is an important way to proactively address future public health and safety issues on coastal beaches.

While we find interesting systematic patterns among beachgoers' information-seeking behaviors, we would also like to address a few limitations of our study in terms of scope and specificity and to qualify the results of our exploratory econometric analysis. We designed the survey questions to be intentionally broad, in part because we were limited in space, and in part because we were interested in general patterns in informationseeking behavior from our respondents. The general nature of our survey responses prevented us from modeling and understanding site-specific relationships. Further, we analyze a sample that is drawn from an intercept sample of beachgoers. Hence, we expect the typical bias and stratification associated with onsite surveys, namely truncation (i.e., the dataset does not include nonusers of Maine and New Hampshire beaches) and endogenous stratification (i.e., people who visit beaches in our study set more frequently 
are more likely to be sampled than those who visit beaches in our study set less frequently) (Shaw 1988, Englin and Shonkwiler 1995). While this limits the application of our results to broader groups of people, our sample does potentially focus on those most at risk (i.e., beachgoers). In addition to sample selection bias, we recognize the potential for endogenous explanatory variables in our regression models, especially with our contact and exposure proxy variables; for example, engagement in beach recreation activities such as swimming could both influence and be influenced by information-seeking behaviors. Finally, while our analysis is performed statically, informationseeking could be viewed as a dynamic problem - beachgoers may learn from information or experiences over time, which may affect their risk perceptions and their behaviors (e.g., Mangel and Clark 1983). Collectively, these limitations bound the interpretation of our findings (e.g., potential for biased coefficients) and offer guidance for future research.

Our study serves as an exploration of the relationship between informationseeking behaviors, experience, and personal characteristics, but we do not intend to imply causality in these results; rather, we believe this research forms a foundation for further study of the factors that drive beach safety information-seeking behavior, and lends itself to some valuable extensions for future work. We identify a need for a more detailed examination of the interactions between information-seeking behavior and beach recreation choices. For those who look to quantify the value of improvements in water quality on our coastal beaches through recreation demand modeling, it may not be valid to assume that beachgoers know about the safety and environmental quality conditions at the beach. Incorporating targeted information-seeking behaviors into site choice models will allow for the evaluation of information-seeking behaviors in the context of measured, sitespecific water quality levels. This approach may advance the understanding of relationships that may exist between information-seeking behaviors and actual conditions and prove invaluable to public health officials charged with ensuring that health and safety information is communicated effectively to beachgoers. In addition, media coverage of harmful events on beaches may affect the way individuals perceive risks on beaches and seek out safety information (McComas 2006, Sunstein and Zeckhauser 2011), as Fein et al (2011) find with risk perceptions and behaviors related to food-borne illnesses. A media analysis of the coverage of illnesses related to water quality or surf-related injuries would help place beach behaviors and risk perceptions in the broad context of information available to beachgoers. Future work that more fully addresses the interactions among beach information and recreation choices offers great potential to inform understanding of decision making and to support improved coastal management. Better assessing the scale at which the individuals search for information, the time they dedicate to finding information, their perceptions of risks, and the relationship between information searching and their intensity of high-contact recreation activities will permit more systematic study of our focal research questions. 
Finally, while understanding the relationship between personal characteristics or behaviors and decisions to seek out safety information is valuable, the act of seeking out information does not necessarily lead to a change in behavior; behavior change occurs over stages, and the framing of information can affect behavioral responses in different ways, depending on the stage (Pelletier and Sharp 2008). Framing should help alert individuals about the intrinsic costs and benefits over extrinsic costs and benefits; this helps motivate behavior changes and the maintenance of these behavior changes over time (Pelletier and Sharp 2008). Building upon this work by exploring the effects of safety information on decisions to visit beaches or engage in high-contact ocean recreation activities will help us conceptualize how diverse beachgoers perceive their risks on coastal beaches and how they modify their behavior in response to safety information.

Our research establishes connections between recreation activity engagement and safety information-seeking behavior. These results begin to fill critical information gaps for coastal resource managers and public health officials who monitor the safety of beaches for public use, but know little about who seeks out this safety information. Better understanding of how users seek out and use safety information becomes increasingly important as future changes in climate and human development near the coast may increase the health and safety risks of coastal recreation.

\section{BIBLIOGRAPHY}

Alberini, A., A.M. Leiter, C.M. Rheinberger, C. McCormick, and A. Mizrahi. 2009. “AVALUATION: Estimating the Economic Value of the Avalanche Bulletin." Proceedings of the International Snow Science Workshop 2009. Davos, Switzerland.

Arcury, T. 1990. "Environmental Attitude and Environmental Knowledge." Human Organization 49(4): 300-304.

Baker-Austin, C., J.A. Trinanes, N.G. Taylor, R. Hartnell, A. Siitonen, and J. Martinez-Urtaza. 2013. "Emerging Vibrio Risk at High Latitudes in Response to Ocean Warming." Nature Climate Change 3(1): 73-77.

Beharry-Borg, N., and R. Scarpa. 2010. "Valuing Quality Changes in Caribbean Coastal Waters for Heterogeneous Beach Visitors." Ecological Economics 69(5): 1124-1139.

Bell, F.W., and V.R. Leeworthy. 1990. "Recreational Demand by Tourists for Saltwater Beach Days." Journal of Environmental Economics and Management 18(3): 189-205.

Bin, O., C.E. Landry, C.L. Ellis, and H. Vogelsong. 2005. “Some Consumer Surplus Estimates for North Carolina Beaches" Marine Resource Economics 20(2): 145-161.

Brannstrom, C., H.L. Brown, C. Houser, S. Trimble, and A. Santos. 2015. "You Can't See Them from Sitting Here': Evaluating Beach User Understanding of a Rip Current Warning Sign.” Applied Geography 56: 61-70.

Byrnes, J.P., D.C. Miller, and W.D. Schafer. 1999. "Gender Differences in Risk Taking: A Metaanalysis." Psychological Bulletin 125(3): 367-383.

Case, D.O., J.E. Andrews, J.D. Johnson, and S.L. Allard. 2005. "Avoiding versus Seeking: The Relationship of Information Seeking to Avoidance, Blunting, Coping, Dissonance, and Related Concepts." Journal of the Medical Library Association: JMLA 93(3): 353-362.

Charron, D.F., M.K. Thomas, D. Waltner-Toews, J.J. Aramini, T. Edge, R.A. Kent, A.R. Maarouf, and J. Wilson. 2004. "Vulnerability of Waterborne Diseases to Climate Change in Canada: 
A Review." Journal of Toxicology and Environmental Health, Part A 67(20-22): 16671677.

Collier, S.A., T.J. Wade, E.A. Sams, M.C. Hlavsa, A.P. Dufour, and M.J. Beach. 2015. “Swimming in the USA: Beachgoer Characteristics and Health Outcomes at US Marine and Freshwater Beaches." Journal of Water and Health 13(2): 531-543.

Cordell, H.K. 2012. "Outdoor Recreation Trends and Futures: A Technical Document Supporting the Forest Service" U.S. Department of Agriculture Forest Service, Southern Research Station, Asheville NC.

Diaz, J.H. 2006. "Global Climate Changes, Natural Disasters, and Travel Health Risks." Journal of Travel Medicine 13(6): 361-372.

Dillman, D.A., J.D. Smyth, and L.M. Christian. 2014. Internet, Phone, Mail, and Mixed-Mode Surveys: The Tailored Design Method (4th ed.). Hoboken, NJ: John Wiley \& Sons.

Doney, S.C., M. Ruckelshaus, J.E. Duffy, J.P. Barry, F. Chan, C.A. English, H.M. Galindo, J.M. Grebmeier, A.B. Hollowed, N. Knowlton, J. Polovina, N.N. Rabalais, W.J. Sydeman, L.D. Talley. 2012. "Climate Change Impacts on Marine Ecosystems." Marine Science 4: 11-37.

Drozdzewski, D., A. Roberts, D. Dominey-Howes, and R. Brander. 2015. "The Experiences of Weak and Non-Swimmers Caught in Rip Currents at Australian Beaches." Australian Geographer 46(1): 15-32.

Eckel, C.C., and P.J. Grossman. 2008. "Men, Women and Risk Aversion: Experimental Evidence." Handbook of Experimental Economics Results 1: 1061-1073.

Englin, J., and J.S. Shonkwiler. 1995. "Estimating Social Welfare Using Count Data Models: an Application to Long-Run Recreation Demand under Conditions of Endogenous Stratification and Truncation." The Review of Economics and Statistics 77: 104-112.

Fein, S.B., A.M. Lando, A.S. Levy, M. F. Teisl, and C. Noblet. 2011. 'Trends in US Consumers' Safe Handling and Consumption of Food and their Risk Perceptions, 1988 through 2010." Journal of Food Protection 74(9): 1513-1523.

Fischhoff, B., A. Bostrom, M.J. Quadrel. 1993. "Risk Perceptions and Communication." Annual Review of Public Health 14(1): 183-203.

Freeman III, A.M., J.A. Herriges, and C.L. Kling. 2014. "Recreation Demand." The Measurement of Environmental and Resource Values: Theory and Methods: 269-309. Third Ed. RFF Press.

Gensini, V.A., and W.S. Ashley. 2010. "An Examination of Rip Current Fatalities in the United States." Natural Hazards 54(1): 159-175.

Gomez, J.M., R. Fajardo, J.F. Patino, and C.A. Arias. 2003. "Necrotizing Fasciitis Due to Vibrio Alginolyticus in an Immunocompetent Patient." Journal of Clinical Microbiology 41(7): 3427-3429.

Greene, W.H. 2003. Econometric Analysis. Pearson Education India.

Haab, T.C., and R.L. Hicks. 1999. Choice Set Considerations in Models of Recreation Demand: History and Current State of the Art. Marine Resource Economics 14(4): 271-281.

Halek, M., J.G. Eisenhauer. 2001. “Demography of Risk Aversion." Journal of Risk and Insurance 68(1): 1-24.

Harding, A.K., D.L. Stone, A. Cardenas, and V. Lesser. 2015. "Risk Behaviors and Self-Reported Illnesses Among Pacific Northwest Surfers." Journal of Water and Health 13(1): 230-242.

Harris, C.R., M. Jenkins, and D. Glaser. 2006. "Gender Differences in Risk Assessment: Why Do Women Take Fewer Risks than Men?" Judgment and Decision Making 1(1): 48-63.

Hausman, J., and D. McFadden. 1984. "Specification Tests for the Multinomial Logit Model." Econometrica: Journal of the Econometric Society 52: 1219-1240.

Hicks, R.L., and I.E. Strand. 2000. "The Extent of Information: Its Relevance for Random Utility Models." Land Economics 76(3): 374-385.

Hilger, J., and M. Hanemann. 2006. "Heterogeneous Preferences for Water Quality: A Finite Mixture Model of Beach Recreation in Southern California." California Sea Grant College Program. 
Howel, D., S. Moffatt, J. Bush, C.E. Dunn, and H. Prince. 2003. "Public Views on the Links between Air Pollution and Health in Northeast England." Environmental Research 91 (3): 163-171.

Jakus, P.M., and W.D. Shaw. 2003. "Perceived Hazard and Product Choice: An Application to Recreational Site Choice." Journal of Risk and Uncertainty 26(1): 77-92.

Jeon, Y., J.A. Herriges, C.L. Kling, and J. Downing. 2005. “The Role of Water Quality Perceptions in Modeling Lake Recreation Demand." The International Handbook on Non-Market Environmental Valuation. Cheltenham, UK: Edward Elgar Publishing.

Kuo, Y., S. Shieh, H. Chiu, and J. Lee. 2007. "Necrotizing Fasciitis Caused by Vibrio Vulnificus: Epidemiology, Clinical Findings, Treatment and Prevention." European Journal of Clinical Microbiology \& Infectious Diseases 26(11): 785-792.

Leatherman, S.P., and S.B. Leatherman. 2011. "Rip Currents: A Major Coastal Hazard and Public Safety Challenge." Solutions to Coastal Disasters 2011: 131-136. ASCE Publications.

Leggett, C.G. 2002. "Environmental Valuation with Imperfect Information the Case of the Random Utility Model." Environmental and Resource Economics 23(3): 343-355.

Lew, D.K., D.M. Larson. 2008. "Valuing a Beach Day with a Repeated Nested Logit Model of Participation, Site Choice, and Stochastic Time Value." Marine Resource Economics 23 (3): 233-252.

Lipset, S.M. 1991. Continental Divide: The Values and Institutions of the United States and Canada. New York, NY: Routledge Press.

Loomis, J., and L. Santiago. 2013. "Economic Valuation of Beach Quality Improvements: Comparing Incremental Attribute Values Estimated from Two Stated Preference Valuation Methods." Coastal Management 41(1): 75-86.

Mallin, M.A., K.E. Williams, E.C. Esham, and R.P. Lowe. 2000. "Effect of Human Development on Bacteriological Water Quality in Coastal Watersheds." Ecological Applications 10(4): 1047-1056.

Mangel, M., and C.W. Clark. 1983. “Uncertainty, Search, and Information in Fisheries.” Journal Du Conseil 41(1): 93-103.

Matthews, B., R. Andronaco, and A. Adams. 2014. “Warning Signs at Beaches: Do They Work?" Safety Science 62: 312-318.

McComas, K.A. 2006. "Defining Moments in Risk Communication Research: 1996-2005." Journal of Health Communication 11(1): 75-91.

Murray, C., B. Sohngen, and L. Pendleton. 2001. "Valuing Water Quality Advisories and Beach Amenities in the Great Lakes." Water Resources Research 37(10): 2583-2590.

National Oceanic and Atmospheric Administration, Office for Coastal Management. 2015. NOAA Report on the U.S. Ocean and Great Lakes Economy. NOAA Office for Coastal Management, Charleston, SC. http://coast.noaa.gov/digitalcoast/publications/econreport (accessed May 2016).

Nicholson, N., E. Soane, M. Fenton-O'Creevy, and P. Willman. 2005. "Personality and DomainSpecific Risk Taking." Journal of Risk Research 8(2): 157-176.

O'Neil, J., T.W. Davis, M.A. Burford, and C. Gobler. 2012. “The Rise of Harmful Cyanobacteria Blooms: The Potential Roles of Eutrophication and Climate Change." Harmful Algae 14: 313-334.

Osimani, B. 2012. "Risk Information Processing and Rational Ignoring in the Health Context." The Journal of Socio-Economics 41(2): 169-179.

Park, C.W., and V.P. Lessig. (1981). "Familiarity and its Impact on Consumer Decision Biases and Heuristics." Journal of Consumer Research 8(2): 223-230.

Parsons, G.R., A.K. Kang, C.G. Leggett, and K.J. Boyle. 2009. "Valuing Beach Closures on the Padre Island National Seashore." Marine Resource Economics 24(3): 213-235.

Patz, J.A., S.J. Vavrus, C.K. Uejio, and S.L. McLellan. 2008. "Climate Change and Waterborne Disease Risk in the Great Lakes Region of the US." American Journal of Preventive Medicine 35(5): 451-458. 
Pendleton, L. 2001. "Exploring the Gap between Measured and Perceived Quality." Los Angeles, Southern California Coastal Ocean Observing System.

Pendleton, L., N. Martin, and D. Webster. 2001. "Public Perceptions of Environmental Quality: A Survey Study of Beach Use and Perceptions in Los Angeles County." Marine Pollution Bulletin 42(11): 1155-1160.

Penn, J., W. Hu, L. Cox, and L. Kozloff. 2016. "Values for Recreational Beach Quality in Oahu, Hawaii." Marine Resource Economics 31(1): 47-62.

Pelletier, L.G., E. Sharp. 2008. "Persuasive Communication and Proenvironmental Behaviors: How Message Tailoring and Message Framing Can Improve the Integration of Behaviors through Self-Determined Motivation." Canadian Psychology 3: 210-217.

Pratap, P.L., R. Sarah, and D. Samuel. 2013. "Improving Water Quality Communications at Beaches: Input from Stakeholders." Journal of Water and Health 11(4): 647-658.

Samuelson, W., and R. Zeckhauser. 1988. "Status Quo Bias in Decision Making." Journal of Risk and Uncertainty 1(1), 7-59.

Scott, S. 2016. "Knowledge in Action: Water Quality Risk, Local Ecological Knowledge, and Decision-making in Maine and New Hampshire's Surfing Population." M.S. Thesis. Center for the Environment, Plymouth State University.

Scott, S. and S.H. Rogers. 2016a. "Riding the Wave of Local Ecological Knowledge in Coastal Research and Management." In prep, Center for the Environment, Plymouth State University, Plymouth, NH.

— 2016b. "Water Quality Impacts on Surfer Perceptions of Risk." In prep, Center for the Environment, Plymouth State University, Plymouth, NH.

Shaw, D. 1988. “On-Site Samples' Regression: Problems of Non-Negative Integers, Truncation, and Endogenous Stratification." Journal of Econometrics 37(2): 211-223.

Slovic, P., M.L. Finucane, E. Peters, and D.G. MacGregor. 2004. "Risk as Analysis and Risk as Feelings: Some Thoughts about Affect, Reason, Risk, and Rationality." Risk Analysis 24 (2): 311-322.

Song, F., F. Lupi, and M. Kaplowitz. 2010. "Valuing Great Lake Beaches." Selected Paper Prepared for Presentation at the Agricultural \& Applied Economics Association 2010 AAEA, CAES, \& WAEA Joint Annual Meeting, Denver, Colorado, 25-27 July 2010.

Stigler, G.J. 1961. "The Economics of Information." The Journal of Political Economy 69(3): 213-225.

Stiglitz, J.E. 2000. "The Contributions of the Economics of Information to Twentieth Century Economics." Quarterly Journal of Economics 115(4): 1441-1478.

Stranger, M. 1999. "The Aesthetics of Risk." International Review for the Sociology of Sport 34 (3): 265-276.

Sunstein, C.R., and R. Zeckhauser. 2011. "Overreaction to Fearsome Risks." Environmental and Resource Economics 48(3): 435-449.

Train, K.E., 2009. Discrete Choice Methods with Simulation. Cambridge, UK: Cambridge University Press.

Tseng, L.Y., S.C. Jiang. 2012. "Comparison of Recreational Health Risks Associated with Surfing and Swimming in Dry Weather and Post-Storm Conditions at Southern California Beaches Using Quantitative Microbial Risk Assessment (QMRA)." Marine Pollution Bulletin 64(5) 912-918.

Turbow, D.J., Kent, E.E., and Jiang, S.C. 2008. "Web-Based Investigation of Water Associated Illness in Marine Bathers." Environmental Research 106(1): 101-109.

Viscusi, W.K. 1991. "Age Variations in Risk Perceptions and Smoking Decisions." Review of Economics and Statistics 73(4): 577-588.

Wade, T.J., R.L. Calderon, K.P. Brenner, E. Sams, M. Beach, R. Haugland, L. Wymer, and A.P. Dufour. 2008. "High Sensitivity of Children to Swimming-Associated Gastrointestinal Illness: Results Using a Rapid Assay of Recreational Water Quality." Epidemiology 19(3): 375-383. 
Wade, T.J., E. Sams, Brenner, K.P., R. Haugland, E. Chern, M. Beach, L. Wymer, C.C. Rankin, D. Love, Q. Li, R. Noble, and A.P. Dufour. 2010. "Rapidly Measured Indicators of Recreational Water Quality and Swimming-Associated Illness at Marine Beaches: a Prospective Cohort Study." Environmental Health 9(66): 1-14.

Yeh, C., T.C. Haab, and B.L. Sohngen. 2006. "Modeling Multiple-Objective Recreation Trips with Choices over Trip Duration and Alternative Sites." Environmental and Resource Economics 34(2): 189-209. 